\title{
MODEL CSR PENGEMBANGAN PARIWISATA BERBASIS MASYARAKAT DI PANTAI TIRTA AYU, DESA BALONGAN, INDRAMAYU
}

\author{
Suci Trianingrum \\ Community Development Officer PT. Pertamina Integrated Terminal Balongan \\ strianingrum@gmail.com
}

\begin{abstract}
This article aims to describe the development of community-based tourism in Balongan Village, Indramayu which began from an initiation of residents to build coastal tourism in 2017. Then the management was then managed by BUMDES and became a CSR partner of PT. Pertamina Integrated Terminal Balongan in 2020. This activity is carried out in the context of environmental corporate social responsibility (TJSL) or known as Corporate Social Responsibility (CSR). This study uses a descriptive qualitative method by interview with beach managers and literature studies to enrich the sources. The results of the study shows that 1) Tirta Ayu Beach is a tourism initiated by residents (local heroes) 2) There is a cooperation between residents who are members of Tirta Ayu beach management (under BUMDES management) and CSR PT. Pertamina Integrated Terminal Balongan through the $D E R M A Y U$ program includes planning, implementation, monitoring, and evaluation regularly so that it follows the 5-year strategic plan 3) the empowerment program at Tirta Ayu Beach can create good relations between residents and companies, generate positive benefits in the economy and create jobs opportunities.
\end{abstract}

Keywords: CSR, Community Based Tourism

\begin{abstract}
Abstrak
Artikel ini bertujuan untuk mendeskripsikan pengembangan pariwisata berbasis masyarakat di Desa Balongan, Indramayu yang diawali dari sebuah inisiasi warga untuk membangun wisata pantai yang dimulai pada tahun 2017. Kemudian pengelolaanya dikelola oleh BUMDES dan pada tahun 2020 menjadi mitra binaan CSR PT. Pertamina Integrated Terminal Balongan. Kegiatan ini dilakukan dalam rangka tanggung jawab sosial perusahaan lingkungan (TJSL) atau yang dikenal dengan Corporate Social Responsibility (CSR). Penelitian ini menggunakan metode kualitatif deskriptif dengan interview para pengelola pantai serta studi literatur untuk memperkaya sumber. Hasil penelitian menunjukkan bahwa 1) Pantai Tirta Ayu merupakan pariwisata yang diinisiasi oleh warga (local hero) 2) Adanya kerjasama antara warga yang tergabung dalam pengelola pantai Tirta Ayu (dibawah BUMDES) dan CSR PT. Pertamina Integrated Terminal Balongan melalui program DERMAYU meliputi perencanaan, implementasi, monitoring dan evaluasi secara berkala sehingga sesuai dengan rencana strategis 5 tahun 3) program pemberdayaan di Pantai Tirta Ayu mampu menciptakan hubungan baik antara warga dan perusahaan, menimbulkan kemanfaatan positif dalam bidang ekonomi serta membuka lapangan pekerjaan.
\end{abstract}

Kata kunci: CSR, Pariwisata Berbasis Masyarakat 


\section{JURNAL PEMBERDAYAAN MASYARAKAT 219 \\ Volume 9 No. 2 Tahun 2021 ISSN: 2355-8679}

\section{PENDAHULUAN}

Dalam satu dekade belakangan ini, tanggung jawab perusahaan menjadi hal yang amat penting bagi perusahaan di Indonesia. Perusahaan tidak hanya dihadapkan pada tanggung jawab untuk memperoleh keuntungan melainkan juga harus memperhatikan aspek sosial serta lingkungan (Disemadi \& Prananingtyas, 2020). Hal ini mengacu pada UndangUndang nomor 40 tahun 2007 tentang Perseroan Terbatas (UUPT) yang menyatakan bahwa Perseroan yang menjalankan kegiatan usahanya dibidang dan atau berkaitan dengan sumber daya alam wajib melaksanakan Tanggung Jawab Sosial dan Lingkungan. Sehingga, melalui undang-undang ini industri wajib melaksanakannya kegiatan tanggung jawab sosial dan Lingkungan.

Konsep CSR sendiri pertama kali dikemukakan pada tahun 1953 oleh Howard R. Bowen, bahwasanya perusahaan berkewajiban melaksanakan tanggung jawab kepada stakeholder dalam kegiatan operasinya untuk memberikan nilai kepada mereka. Stakeholder yang dimaksud adalah para karyawan, konsumen, masyarakat, komunitas lokal, pemerintah dan Lembaga swadaya masyarakat (Marthin et al., 2018). Kemudian pada perkembangannya CSR tidak lagi sekedar dimaknai sebagai sebuah aktivitas derma atau karitatif yang dilakukan oleh pihak perusahaan, paradigma baru mengarahkan bahwa CSR menjadi sebuah bentuk komitmen perusahaan dalam melakukan tanggung jawab kepada masyarakat dan lingkungan serta pembangunan ekonomi mandiri yang berkelanjutan, lahirnya paradigma tersebut seiring dengan lahirnya konsep pembangunan berkelanjutan (Pranoto \& Yusuf, 2016).

Selain itu, pada tahun 2004, ISO (International Organization for Standardization) sebagai sebuah induk organisasi standarisasi internasional menginisiasi lahirnya panduan dan standarisasi untuk tanggung jawab perusahaan yang diberi nama ISO 26000: Guidance Standard on Social Responsibility. ISO 26000 menyediakan standar pedoman yang bersifat sukarela mengenai tanggung jawab sosial suatu institusi berupa 7 isu pokok, yakni 1) pengembangan masyarakat, 2) konsumen, 3) praktek kegiatan institusi yang sehat 4) lingkungan 5) ketenagakerjaan 6) hak asasi manusia 7) organisasi pemerintah. ISO 26000 menerjemahkan tanggung jawab sosial sebagai suatu komitmen terhadap masyarakat dan lingkungan melalui perilaku yang transparan dan etis dengan secara konsisten melakukan pembangunan perkelanjutan dan kesejahteraan masyarakat, memperhatikan kepentingan dari para stakeholder, sesuai dengan hukum yang berlaku dan konsisten dengan norma-norma internasional, serta terintegrasi di seluruh aktivitas organisasi, baik produk maupun jasa. 


\section{JURNAL PEMBERDAYAAN MASYARAKAT 220 \\ Volume 9 No. 2 Tahun 2021 ISSN: 2355-8679}

PT. Pertamina Integrated Terminal Balongan merupakan perusahaan yang bergerak di distribusi minyak dan gas dibawah subholding distribusi Marketing Operation Region 3 (MOR 3). PT. Pertamina Integrated Terminal Balongan bertugas untuk mensuplay pasokan minyak dan gas di area jawa bagian barat, meliputi Jawa Barat, Banten dan Jakarta. PT. Pertamina Integrated Terminal Balongan berlokasi di Desa Balongan dengan luas seluas 62 Ha, dengan desa penyanggga di sekitar seperti Desa Sukaurip, Desa Balongan dan Desa Tegalurung.

Desa balongan merupakan desa yang terletak di kabupaten indaramayu, letaknya dekat dan bersebelahan langsung dengan perusahaan, yakni PT. Pertamina Integrated Terminal Balongan. Maka penting bagi hadirnya perusahaan untuk menjaga keberlangsungan lingkungan serta hubungan harmonis antara pihak pemangku kepentingan dan masyarakat agar terhindar dari konflik dan gesekan serta keberlanjutan lingkungan. Perusahaan yang dalam hal ini menempati posisi sebagai shareholder harus mempunyai kebijakan yang berkaitan dengan pihak-pihak yang terkait dengan dampak operasional perusahaan, seperti pekerja, pemerintah setempat dan masyarakat (Disemadi \& Prananingtyas, 2020).

PT. Pertamina Integrated Terminal Balongan melihat bahwa Desa Balongan memiliki potensi sumber daya alam yang beragam, seperti hamparan laut, tambak milik warga, lahan pertanian. Maka penting bagi perusahaan untuk menstimulus potensi desa yang ada disana sehingga menjadi lebih bermanfaat bagi masyarakat. Salah satunya adalah Pantai Tirta Ayu. Pantai Tirta Ayu berlokasi di blok pesisir, Desa Balongan. Pada awalnya pantai ini dikelola secara swadaya oleh masyarakat. Kemudian pada tahun 2020 menjadi mitra binaan pertamina dengan program DERMAYU (Desa Wisata Pantai Tirta Ayu) melakukan pembenahan dari segi sarana dan prasarana serta pendampingan.

Program DERMAYU diharapkan dapat membawa kebermanfaatan, seperti memberikan peluang ekonomi, membuka lapangan pekerjaan lapangan pekerjaan dan turut andil dalam menambah pendapatan desa. Kemudian, lebih lanjut, artikel ini akan memaparkan model tanggung jawab perusahaan dalam pengembangan pariwisata di Pantai Tirta Ayu, Indramayu, Jawa Barat, tahapan tahapan yang dilakukan dalam proses pemberdayaan dan bagaimana kontribusi Pertamina melalui program DERMAYU ini dapat bermanfaat bagi masyarakat sekitar perusahaan. 


\section{JURNAL PEMBERDAYAAN MASYARAKAT $\mid 221$ \\ Volume 9 No. 2 Tahun 2021 ISSN: 2355-8679}

\section{METODE PENELITIAN}

Penelitian ini menggunakan Metode kualitatif deskriptif dengan pendekatan yang dilakukan adalah studi kasus dengan melihat secara dekat pengembangan wisata Pantai Tirta Ayu sebagai program pemberdayaan dalam implementasi kegiatan Corporate Social responsibility PT. Pertamina Integrated Terminal Balongan. Pengumpulan data dalam penelitian ini dilakukan melalui studi kepustakaan, observasi 1 partisipan dengan jumlah 4 orang narasumber, wawancara serta kajian teoritis pada penelitian yang pernah dilakukan. Fokus penelitian ini adalah tahapan pelaksanaan program Corporate Social responsibility yang dilakukan PT. Pertamina Integrated Terminal Balongan dengan lokus di Blok Pesisir, Desa Balongan, Kec. Balongan, Indramayu, Jawa Barat. Pengambilan data pada penelitian ini menggunakan pendekatan purposive sampling yakni para pengelola Pantai Tirta Ayu sebagai informan kunci dalam penelitian ini.

\section{HASIL DAN PEMBAHASAN}

\section{Inisiasi Aktor dalam Pengembangan Desa Wisata Pantai Tirta Ayu}

Program DERMAYU (Desa Wisata Pantai Tirta Ayu) merupakan program yang dilaksanaakan oleh PT. Pertamina Integrated Terminal Balongan. Program tersebut merupakan upaya antara warga, pihak perusahaan dan pemerintah desa setempat melakukan optimalisasi potensi berupa daratan pantai yang dapat dijadikan tempat berwisata yang berada di Blok Pesisir, Desa Balongan, Indramayu, Jawa Barat. Tidak hanya optimalisasi potensi pantai saya tetapi PT. Pertamina IT Balongan mendukung upaya penghijauan pantai dengan melakukan penanaman 1000 pohon cemara laut.

Pada awalnya, Pantai Tirta Ayu adalah sebuah pantai tersembunyi di Desa Balongan, pantai yang tidak terurus dan hanya ramai Ketika hari lebaran. Melihat peluang adanya potensi pariwisata kemudian Pantai Tirta Ayu dikembangkan langsung oleh dua warga Desa Balongan, yakni Bapak Dasuki dan Bapak Gunawan yang tempat tinggalnya tidak jauh dari lokasi pengembangan pantai. Mereka menangkap bahwa lanskap pantai ini akan berpotensi menjadi tempat wisata. Setiap hari mereka melakukan pembenahan secara swadaya, membersihkan semak-semak belukar yang mengganggu keindahan pantai, membersihkan sampah-sampah laut yang mengotori bibir pantai. Sampai pada akhirnya tahun 2017, pengelolaan pantai tersebut dialihkan menjadi bagian unit usaha milik BUMDES dan mendapat bantuan dana pembangunan kios untuk warga yang ingin berjualan disana. 


\section{JURNAL PEMBERDAYAAN MASYARAKAT 222 \\ Volume 9 No. 2 Tahun 2021 ISSN: 2355-8679}

Selain bantuan dari BUMDES untuk pengembangan pantai juga mendapat bantuan dari Kementerian Desa untuk membangun kamar mandi. Seiring berjalannya waktu, pantai tersebut ramai didatangi wisatawan lokal. Nama Tirta Ayu sendiri diambil karena mempunyai filosofi, yakni dari seorang Nyai yang bernama Nyi Mas Ayu yang konon petilasannya berada didekat pantai tersebut. Sehingga disebutlah area pantai tersebut menjadi Pantai Tirta Ayu. Gunawan dan Dasuki setiap hari tergerak untuk babat alas. Dibantu oleh Bapak Akmin sebagai ketua di bidang pengembangan paniwisata BUMDES mereka memanfaatkan barangbarang bekas yang bisa dimanfaatkan. Seperti ban bekas, kayu bekas. Inisiatif pengelola memanfaatkan barang bekas untuk di upcycling menjadi unit-unit untuk foto selfie bagi pengunjung yang singgah kesana.

Hingga pada tahun 2020, Pantai Tirta Ayu menjadi mitra binaan PT. Pertamina Integrated Balongan, perbaikan dasar dilakukan antara pihak perusahaan dan pengelola pantai dan menjadikan Pantai Tirta Ayu menjadi satu program pemberdayaan yang bernama DERMAYU (Desa Wisata Pantai Tirta Ayu). Program ini meliputi perbaikan sarana dan prasarana yang ada di dalam pantai, peningkatan manajemen pariwisata dan sapta pesona, peningkatan bagi mitigasi bencana, serta peningkatan atraksi wisata sehingga menjadi daya tarik wisatawan yang akan berkunjung disana. Diharapkan mampu memberikan pemerataan ekonomi di desa dan memberikan peluang lapangan pekerjaan bagi masyarakat lokal.

\section{Tahapan Program CSR Desa Wisata Pantai Tirta Ayu}

Sesuai dengan klausul ISO 26000, sebagai bagian dari tanggung jawab sosial peusahaan, PT. Pertamina Integrated Terminal Balongan kemudian mengenali dan mengidentifikasi stakeholder yang terdampak dan yang memberi dampak dari proses operasi bisnis perusahaan. Sehingga, untuk itu, PT. Pertamina Integrated Terminal Balongan melakukan kegiatan mengenali kondisi sosial dan ekonomi masyarakat sekitar, sehingga setiap program yang dijalankan dapat tepat sasaran dan sesuai dengan kebutuhan masyarakat. Berikut merupakan tahapan pemberdayaan masyarakat yang dilakukan oleh Corporate Social Responibility (CSR) PT. Pertamina Integrated Terminal Balongan:

\section{Perencanaan}

Program DERMAYU dilaksanakan berdasarkan social mapping yang dilakukan oleh PT. Pertamina Integrated Terminal Balongan bekerjasama dengan lembaga independen yang bergerak pada penelitian sosial dan inovasi sosial. Dari penelitian tersebut menghasilkan sebuah dokumen yang memaparkan mengenai potensi Desa Balongan, dari menggali, 
mengenali, memetakan komunitas sasaran, kebutuhan serta harapan masyarakat khususnya di wilayah Ring 1, yakni wilayah yang terdampak langsung dari operasi perusahaan.

Dari segi geografis, Desa Balongan merupakan daerah pesisir industri. Wilayahnya merupakan dataran rendah dengan topografi 1 meter diatas permukaan laut (MDPL) (Inovasi sosial, 2020). Luas wilayah Desa Balongan adalah 511 ha dengan jumlah penduduk sebanyak 5.569 orang. Desa ini berbatasan langsung dengan Laut Jawa di sebelah Utara yang kaya akan sumber daya alam seperti pertanian dan juga potensi perikanan air laut dan payau berupa tambak ikan bandengn dan juga udang.

Dokumen social mapping dapat digunakan untuk memotret potensi-potensi tersembunyi yang nantinya dapat dijadikan program pemberdayaan masyarakat. Dari dokumen pemetaan sosial, perusahaan dapat menelaah ekspektasi, permasalahan dan potensi masyarakat di sekitar peusahan yang dijadikan bahan dalam merumuskan program CSR sebagai pemicu perbahan masyarakat menjadi lebih baik dan mandiri serta sebagai bahan mengelola hubungan harmonis antara seluruh stakeholder yang berkepentingan. Dokumen social mapping menjadi dasar bagi PT. Pertamina Integrated Terminal Balongan untuk menentukan dan merumuskan Rencana Kerja dan Rencana Strategis 5 tahun.

Selain dokumen social mapping, pemberdayaan masyarakat program DERMAYU juga mempunyai dokumen rencana strategis 5 tahun hasil focus group discussion dengan masyarakat, hal ini dilakukan agar terdapat partisipasi masyarakat sehingga memunculkan program pemberdayaan yang bukan top down, tetapi bottom up. Hal ini dipahami pihak perusahaan bahwasanya masyarakat sebagai subjek atau pelaku pembangunan, yang mana mengandung arti bahwa masyarakat menjadi pelaku penting yang harus terlibat aktif dalam proses perencanaan dan pengembangan kepariwisataan, bersama-sama dengan pemangku kepentingan terkait lainnya. Dalam fungsinya, sebagai subjek, masyarakat memiliki peran dan tanggung jawab untuk bersama-sama mendorong keberhasilan pengembangan keparisiwataan di wilayahnya (Firmansyah Rahim, 2012).

Setelah memiliki dokumen Rencana Strategis 5 tahun, maka setelah itu adalah melakukan break down dokumen tersebut menjadi rencana kerja tahunan. Rencana Kerja program DERMAYU di tahun 2020 meliputi banyak kegiatan, hal tersebut dikarenakan di tahun pertama ini, program DERMAYU masih banyak yang perlu diperbaiki dari segi sarana dan prasarana dasar sebagai daerah wisata. Daerah wisata perlu mementingkan aspek 3A, yakni aspek Amenitas, Atraksi dan Akomodasi. Maka di tahuun 2020 ini program DERMAYU memfokuskan pada perbaikan sarana dan sarana dasar, seperti perbaikan kamar 


\section{JURNAL PEMBERDAYAAN MASYARAKAT $\mid 224$ \\ Volume 9 No. 2 Tahun 2021 ISSN: 2355-8679}

mandi dan kamar bilas. Pengadaan bak sampah, pembuatan tempat pembuangan sampah sementara, perbaikan gudang, penanaman pohon cemara dan pengadaan taman bermain anak.

\section{Implementasi}

Setelah proses perencanaan program pemberdayaan melibatkan masyarakat selesai, maka tahapan selanjutnya adalah tahapan implementasi program. Implementasi program disesuaikan dengan rencana kerja yang sudah dibuat dalam setahun, mencakup kegiatan, indicator kegiatan, jadwal pelaksanaan kegiatan dan kesesuaian target sasaran. Hal tersebut penting dilakukan agar program sesuai dengan track yang sudah di buat. Namun jikapun kegiatan mengalami Kendala seperti halnya pandemic covid yang tengah melanda sehingga jadwal yang sudah ditentukan tidak sesuai dengan perencanaan hal tersebut tidak masalah, tentu yang utama adalah komunikasi antar pendamping sosial atau fasilitator lapangan dengan kelompok binaan.

Dalam tahap implementasi, masyarakat menduduki posisi sebagai bagian integral yang ikut berperan baik sebagai subyek maupun obyek pembangunan itu sendiri (Wiwin, 2018). Masyarakat merupakan bagian yang tidak bisa terpisahkan dari pariwisata, sehingga, pariwisata berbasis masyarakt memiliki berbagai kelebihan baik dari aspek pengembangan masyarakat maupun industri pariwisata itu sendiri. Community based tourism muncul sebagai sebuah alternatif dari arus utama pengembangan pariwisata, masyarakat ditempatkan sebagai pengontrol dan terlibat langsung dalam manajemen pengembangan parisiwsata.

Dalam implementasi program, proses yang dilakukan tidak bisa dirasakan cepat karena pemberdayaan merupakan serangkaian tindakan yang dilakukan secara kronologis dan sistematis yang mencerminkan tahapan untuk mengubah pihak yang kurang atau belum berdaya menuju keberdayaan. Pariwisata berbasis masyarakat merupakan sebuah pendekatan pemberdayaan yang melibatkan dan meletakkan masyarakat sebagai pelaku penting dalam konteks paradigma baru pembangunan yakni pembangunan yang berkelanjutan (sustainable development paradigma) (Sastrayuda, 2010). Pariwisata berbasis masyarakat merupakan peluang untuk menggerakkan seluruh potensi dan dinamika masyarakat. Pariwisata berbasis masyarakat tidak berarti merupakan upaya kecil dan lokal semata, tetapi perlu diletakkan dalam konteks kerjasama masyarakat secara keseluruhan.

Implementasi program DERMAYU mengalami banyak kendala, salah satunya adalah abrasi laut yang terjadi pada akhir tahun 2020, sehingga mengakibatkan taman bermain dan gazebo di pantai rusak. Kerusakan akibat abrasi laut yang cukup parah ini kemudian menjadi 
bahan untuk evaluasi dan pengkajian di perencanaan program tahun berikutnya agar dapat meminimalisir dan juga mencegah abrasi pantai di kemudian hari.

Implementasi program DERMAYU tidak bisa terlepas dari peran pengelola. Karena pengelola mempunyai peran sentral dalam pelaksanaan program. Disini pengelola pantai Tirta Ayu mempunyai relasi yang cukup kuat. Mereka secara swadaya setiap hari melakukan perbaikan dan perawatan area pantai. Koordinasi terjalin antara 3 aktor utama pengelola pantai Tirta Ayu, yakni pak Dasuki, Pak Akmin dan juga pak Gunawan.

\section{Monitoring dan Evaluasi}

Tahap selanjutnya adalah monitoring dan evaluasi, dalam tahapan ini PT. Pertamina Integrated Terminal Balongan mempunyai sistem tata Kelola monitoring dan evaluasi masyarakat. Dalam hal tersebut Maka dilakukan Monitoring dan evaluasi berkala. Monitoring dilaksanakan setiap triwulan sekali dengan form monitoring yang sudah disediakan oleh perusahaan. Kemudian untuk evaluasi dilaksanakan dalam dua tahap, yakni evaluasi ongoing program yang dilakukan bersamaan dengan kegiatan monitoring pada setiap tahapan kegiatan, tujuannya ketika ditemukan permasalahan dapat segera diarahkan dan dilakukan perbaikan. Selain itu adalah evaluasi post program, dilakukan setelah program selesai untuk melihat keseluruhan program dari perencanaan hingga pelaksanaan.

Prinsip monitoring dan evaluasi program pemberdayaan DERMAYU ini dilakukan terencana dan partisipatif melibatkan kelimpok binaan dan stakeholder terkait lainnya, selain itu monitoring dan evaluasi dilakukan dengan mengacu pada indicator dan parameter program yang telah ditetapkan pada rencana kerja tahunan.

Pada akhir tahun 2020 yakni setelah semua kegiatan sudah selesai dilakukan maka Tim CSR PT. Pertamina Integrated Terminal Balongan melakukan perhitungan Indeks Kepuasan Masyarakat yang meliputi 5 aspek, yakni aspek perencanaan, aspek pendanaan, aspek pendampingan, aspek pelaksananan program dan aspek keberlanjutan program. Form Indeks Kepuasan Masyarakat menjaring 6 responden yang mana mereka merupakan penerima manfaat program DERMAYU. Menurut data perhitungan Indeks Kepuasan Masyarakat pada program DERMAYU, memuat nilai 3,65 atau pada skor 91,25 dengan keseluruhan nilai indicator hasilnya adalah A yaitu sangat baik (Indonesia, 2020). Sehingga secara umum masyarakat penerima manfaat program DERMAYU merasa puas dengan kinerja mutu program DERMAYU.

Menurut hasil analisis tersebut yang perlu ditingkatkan adalah aspek pelaksanaan dan perencanaan program dengan rekomendari untuk keberlanjutan program DERMAYU yaitu 
perlu perbaikan akses jalan masuk menuju Pnatai Tirta Ayu, penambahan fasilitas untuk pengolahan sampah, perlunya strategi marketing untuk menarik pengunjung datang lebih banyak dan pendampingan serta pendanaan hingga benar-benar mandiri.

\section{Kontribusi Program Pemberdayaan Masyarakat DERMAYU terhadap masyarakat Desa Balongan}

Di tahun pertama program DERMAYU ini berjalan, pengelola pantai sebagai penerima manfaat mendapatkan kebermanfaat, menurut Bapak Gunawan, selaku salah satu pengelola dan inisiator pengembangan Pantai Tirta Ayu menyatakan bahwa pendapatan yang didapatkan dari kunjungan di Pantai Tirta Ayu bertambah, walaupun untuk hari biasa jumlah pengunjung hanya mencapai 50 orang, namun di hari libur dapat mencapai 200an orang. Pendapatan pada hari libur hari besar bisa mencapai Rp 500.000 setiap harinya, apalagi Ketika libur lebaran dan libur akhir tahun. Pendapatan yang diperoleh dari pengunjung ini kemudian dialokasikan sebanyak 30\% untuk BUMDES, sisanya dibagikan untuk pengelola dan pekerja dan juga untuk biaya maintenance sarana prasana Pantai Tirta Ayu. Tidak hanya keuntungan bagi pengelola saja, namun warga yang menjual dagangannya dan kuliner berupa masakan laut (sea food) dan snack serta minuman meningkat pendapatannya, untuk satu hari di hari libur, pendapatan kotor penjual warga sebanyak rata-rata Rp 1.500.000. jumlah itu dinilai memberikan dampak positif bagi warga yang berjualan diwarung-warung dekat pantai.

Namun, selain dampak positif bagi masyarakat penerima manfaat, program ini masih jauh dari cukup. Banyak kekurangan dan perbaikan secara terus menerus agar nantinya program ini menciptakan kemandirian masyarakat. Dalam pelaksanaan di tahun pertama ini, masyarakat masih tertutup dengan pemerintah lewat dinas pariwisata sehingga untuk manajemen kepariwisataan di Pantai Tirta Ayu belum mencerminkan sapta pesona dan system majerial masih kurang. Masyarakat beranggapan bahwa dengan hadirnya dinas akan mengambil pendapatan mereka menjadi pendapatan daerah (PAD), sehingga mereka masih menutup diri dari dinas dan pemerintahan terkait. Melihat hal tersebut, belum adanya sinergitas antara masyarakat, swasta dan pemerintah sehingga perlu waktu secara perlahan lewat pendampingan dan edukasi kepada masyarakat agar mereka bisa memahami pentinya sinergitas antar ketiganya tanpa paksaan. Sehingga nantinya dapat mencapai sistem manajerial parisiwata yang bagus dan pemahaman mengenai sapta pesona serta penguatan kelembagaan yang kokoh. 


\section{KESIMPULAN}

Program pemberdayaan pengembangan pariwisata berbasis masyarakat (program DERMAYU) yang dijalankan antara CSR PT. Pertamina Integrated Terminal Balongan dan pengelola Pantai Tirta Ayu (dibawah BUMDES) memberikan kebermanfaatan dari segi peningkatan ekonomi dan terbukanya lapangan pekerjaan. Adapun tahapan pemberdayaan masyarakat yang dilakukan adalah mulai dari tahap perencanaan, yakni dari pembuatan dokumen social mapping, pembuatan renstra dan renja, kemudian tahap implementasi berupa kegiatan yang dijalankan sesuai renja meliputi: penanaman pohon cemara, perbaikan sarana prasarana kamar bilas dan toilet, perbaikan gudang, pembuatan taman bermain anak, penyediaan tempat pembuangan sampah dan pembangunan tempat pembuangan sampah sementara. Kemudian tahapan monitoring serta evaluasi meliputi evaluasi on going dan evaluasi post program.

Tahapan pemberdayaan tersebut dilakukan dengan memposisikan masyarakat, dalam hal ini adalah pengelola pantai tirta ayu sebagai subjek utama dalam pemberdayaan, sehingga partisipasi mereka sangat dibutuhkan untuk keberlanjutan program. Namun, pada perkembangannya, program DERMAYU masih jauh dari kata cukup, hal ini dikarenakan program ini masih satu tahun berjalan, sehingga perlu adanya keberlanjutan dari segi perencanaan dan pelaksanaan serta pendampingan seperti perbaikan manajemen pariwisata agar terwujud program Desa Wisata Pantai Tirta Ayu (DERMAYU) yang dapat menciptakan kemandirian bagi masyarakat Desa Balongan.

\section{DAFTAR PUSTAKA}

Disemadi, H. S., \& Prananingtyas, P. (2020). Kebijakan Corporate Social Responsibility (CSR) sebagai Strategi Hukum dalam Pemberdayaan Masyarakat di Indonesia. Jurnal Wawasan Yuridika, 4(1), 1. https://doi.org/10.25072/jwy.v4i1.328

Firmansyah Rahim. (2012). Buku Pedoman Kelompok Sadar Wisata Di Destinasi Pariwisata. 56.

Marthin, M., Salinding, M. B., \& Akim, I. (2018). Implementasi Prinsip Corporate Social Responsibility (Csr) Berdasarkan Undang-Undang Nomor 40 Tahun 2007 Tentang Perseroan Terbatas. Journal of Private and Commercial Law, 1(1), 111-132. https://doi.org/10.15294/jpcl.v1i1.12358

Pranoto, A. R., \& Yusuf, D. (2016). Program CSR Berbasis Pemberdayaan Masyarakat Menuju Kemandirian Ekonomi Pasca Tambang di Desa Sarij aya. Jurnal Ilmu Sosial Dan Ilmu Politik, 18(1), 39. https://doi.org/10.22146/jsp.13094

Wiwin, I. W. (2018). Community Based Tourism Dalam Pengembangan Pariwisata Bali. Pariwisata Budaya, 3(1), 69-75. 


\section{JURNAL PEMBERDAYAAN MASYARAKAT $\mid 228$ \\ Volume 9 No. 2 Tahun 2021 ISSN: 2355-8679}

Indonesia, I. S. (2020). Indeks Kepuasan Masyarakat dalam Program CSR PT. Pertamina Integrated Terminal Balongan. Bandung.

Sastrayuda, G. (2010). Strategi Pengembangan dan Pengelolaan Resort and Leisure . 